\title{
Physician suicide
}

\author{
Joy Albuquerque MD MSc, Sarah Tulk MD MSc
}

Cite as: CMAJ 2019 May 6;191:E505. doi: 10.1503/cmaj.181687

CMAJ Podcasts: author interview at https://soundcloud.com/cmajpodcasts/181687-five

\section{1} Suicide is an occupational hazard for physicians

Suicide is the only cause of mortality that is higher in physicians than nonphysicians. Compared with nonphysicians, male physicians are $40 \%$ more likely to die by suicide (rate ratio $1.41,95 \%$ confidence interval [CI] 1.21-1.65), and the risk to female physicians is more than doubled (rate ratio $2.27,95 \% \mathrm{Cl} 1.90-2.73){ }^{1}$

2 Firearms, poisoning and blunt force trauma are the most common means of suicide among physicians

Whereas firearms are the most common suicide method in both physicians and nonphysicians, physicians are more likely than nonphysicians to use poisoning and blunt force trauma. The increased use of poisoning may be owing to increased access, as physicians who completed a suicide were more likely to have benzodiazepines (odds ratio [OR] $21.0,95 \% \mathrm{Cl}$ 11.4-38.6), barbiturates (OR 39.5, 95\% Cl 15.8-99.0) or antipsychotics (OR 28.7, 95\% $\mathrm{Cl} 7.94-103.9)$ detectable in their blood. ${ }^{2}$

\section{3}

\section{Increased suicidal ideation begins in medical school}

In a recent meta-analysis, the prevalence of suicidal ideation among medical students was $11.1 \%$. In analyses subdivided by time, $7.4 \%$ of students reported suicidal ideation within the past 2 weeks, and $24.2 \%$ within the past year. ${ }^{3}$

\section{Regulatory complaints are associated with increased rates of} suicidal ideation

In a cross-sectional survey of nearly 8000 physicians in the United Kingdom, those with either a past or current regulatory complaint were significantly more likely to report suicidal ideation. Physicians without complaints reported suicidal ideation at a rate of $2.5 \%$, but this was increased to $9.3 \%$ in those with a current or recent complaint (relative risk 3.78, 95\% $\mathrm{Cl} 2.68-$ 5.32 ) and $13.4 \%$ in those with a past complaint (relative risk $5.39,95 \% \mathrm{Cl}$ $3.99-7.30) .^{4}$

\section{Suicidal physicians face unique barriers to care}

Suicidal physicians encounter additional barriers to care, compared with the general population. Whereas both groups face concerns about stigma, lack of time and lack of access to care, physicians have the added burden of concerns regarding confidentiality, and fear of discrimination in licensing and applications for hospital privileges. ${ }^{5}$

\section{References}

1. Schernhammer ES, Colditz GA. Suicide rates among physicians: a quantitative and gender assessment (meta-analysis). Am J Psychiatry 2004;161:2295-302.

2. Gold KJ, Sen A, Schwenk TL. Details on suicide among US physicians: data from the National Violent Death Reporting System. Gen Hosp Psychiatry 2013;35:45-9.

3. Rotenstein LS, Ramos MA, Torre M, et al. Prevalence of depression, depressive symptoms, and suicidal ideation among medical students: a systematic review and metaanalysis. JAMA 2016;316:2214-36.

4. Bourne $T$, Wynants $L$, Peters $M$, et al. The impact of complaints procedures on the welfare, health and clinical practise of 7926 doctors in the UK: a cross-sectional survey. BMJ Open 2015;5:e006687.

5. Center C, Davis M, Detre T, et al. Confronting depression and suicide in physicians: a consensus statement. JAMA 2003; 289:3161-6.

Competing interests: Joy Albuquerque is medical director of the Ontario Medical Association's Physician Health Program. No other competing interests were declared.

This article has been peer reviewed.

Affiliations: Physician Health Program (Albuquerque) Ontario Medical Association; Department of Psychiatry (Albuquerque), University of Toronto, Toronto, Ont.; Department of Family Medicine (Tulk), McMaster University, Hamilton, Ont.

Correspondence to: Sarah Tulk, sarah.tulk@ medportal.ca 